\title{
Convenções de gênero, sexualidade e violência: pesquisa com participantes de eventos do Orgulho LGBT de São Paulo - 2009
}

\author{
Regina Facchini* \\ Isadora Lins França*
}

Resumo: Este artigo procura contribuir com o debate sobre preconceito, discriminação e violência no campo dos estudos de gênero e sexualidade a partir da análise de entrevistas em profundidade realizadas com participantes dos eventos do Orgulho LGBT de São Paulo - 2009 que afirmaram já ter sofrido algum tipo de violência em razão da sua sexualidade. Na primeira parte do artigo, abordamos o modo como categorias de acusação referentes a gênero e sexualidade se integram a dinâmicas de exclusão e violência com as quais as pessoas têm de lidar desde a infância e adolescência, em meio a diferentes convenções de gênero e sexualidade. Na segunda parte, o foco recai sobre as experiências de violência relatadas nas entrevistas e sobre os processos pelos quais tais experiências são transformadas em narrativas a partir de diferentes contextos.

Palavras-chave: violência; gênero; sexualidade; homofobia; LGBT

\begin{abstract}
This article aims to collaborate with the debate about prejudice, discrimination and violence in the field of gender and sexuality studies. In-depth interviews with participants of the LGBT Pride Parade of Sao Paulo - 2009 who mentioned have been victims of violence related to sexuality are sources for the analysis. The first part of the article approaches categories of accusation referred to gender and sexuality and how they are integrated to dynamics of exclusion and violence which people have to deal with since childhood and adolescence. The second part brings the focus to experiences of violence mentioned in interviews, emphasizing the processes by which these experiences are turned into narratives in different contexts.
\end{abstract}

Keywords: violence; gender; sexuality; homophobia; LGBT

\footnotetext{
* Doutora em Ciências Sociais, pesquisadora do Núcleo de Estudos de Gênero - Pagu e professora do Programa de Doutorado em Ciências Sociais, ambos da Unicamp; contato: rfacchini@uol.com.br

** Doutora em Ciências Sociais, pesquisadora de pós-doutorado do Núcleo de Estudos de Gênero - Pagu da Unicamp; contato: isadora.lins@uol.com.br
}

Latitude, Vol. 7, no 1, pp. 13-32, 2013. 
Convenções de gênero, sexualidade e violência: pesquisa com participantes de eventos do Orgulho LGBT de São Paulo - 2009.

Os estudos sobre violência com base na (homo)sexualidade ou performance de gênero têm ganhado mais visibilidade e se consolidado na última década no Brasil, integrando um processo de crescimento e diversificação do campo de estudos sobre sexualidade - ou na articulação entre gênero e sexualidade (RAMOS, 2005). Embora seja importante considerar as iniciativas pioneiras do professor e ativista Luiz Mott $(1997,2000)$ na direção de fazer reconhecer a existência da violência em razão da sexualidade tendo como fonte a compilação dos casos de violência letal noticiados pela imprensa, é preciso notar que abordagens que procuram adensar o conhecimento sobre as dinâmicas da violência atingindo pessoas situadas no espectro do que se convencionou chamar de LGBT (lésbicas, gays, bissexuais, travestis e transexuais) são ainda um tanto recentes. Tendo em vista esse panorama, este artigo tem por objetivo colaborar com as reflexões que se vêm tecendo nesse campo de estudos a partir da análise dos resultados de uma pesquisa integrando dados quantitativos e qualitativos com LGBT que relataram ter sofrido preconceito, discriminação e/ou violência em razão da sexualidade.

Consideramos estar dialogando com um conjunto de reflexões e pesquisas que pode ser indicado a partir da categoria homofobia, que tem se consolidado no vocabulário político e acadêmico no Brasil com vistas a nomear uma variedade de expressões da violência em razão da sexualidade e performance de gênero ${ }^{1}$. Embora as pesquisas sobre homofobia no Brasil ainda sejam escassas, há pelo menos duas frentes de estudos que nos ajudam a pensar a dinâmica desse fenômeno que

${ }^{1} \mathrm{O}$ presente artigo é produto do projeto "Implantação da área de pesquisa Diversidade sexual, poder e diferença no Núcleo de Estudos de Gênero Pagu/Unicamp", executado entre 2009 e 2011 pelo Núcleo de Estudos de Gênero - Pagu da Unicamp, com apoio da Secretaria Especial de Direitos Humanos da Presidência da República. O subprojeto "Convenções de gênero, sexualidade e violência entre LGBT na Grande São Paulo", de onde provêm os dados aqui trabalhados, foi coordenado por Regina Facchini e conduzido em parceria com Isadora Lins França, contando com o apoio de uma equipe de mais 18 pesquisadores de campo nos eventos do Orgulho LGBT de São Paulo em 2009. Agradeçemos aos integrantes da equipe: Marcelo Daniliauskas (mestre em Sociologia da Educação - FE/USP) atuou na etapa quantitativa da pesquisa como entrevistador, analisando os dados e colaborou na elaboração de relatório dessa etapa; Anna Paula Vencato (Doutora em Antropologia pela UFRJ) co-coordenou o campo na etapa quantitativa; Christiano Tambascia (Doutor em Antropologia pela Unicamp) atuou na seleção de potenciais entrevistados na etapa quali e na sistematização de entrevistas em profundidade; Ana Claudia Pilon, Jonatan Jackson Sacramento e Thiago Henrique de Oliveira Falcão (graduandos em Ciências Sociais pelo IFCH/Unicamp) colaboraram na transcrição de entrevistas e na elaboração do banco de dados da etapa quanti. 
Regina Facchini

Isadora Lins França

emerge no cotidiano dos sujeitos. Por um lado, temos pesquisas como as realizadas com jovens, estudantes ou população em geral em diferentes localidades brasileiras e que indicam a forte presença de preconceitos e discriminação relacionados às homossexualidades.

Tomemos como exemplo dessa primeira frente os dados da pesquisa realizada pela Fundação Perseu Abramo: embora 92\% dos respondentes identifique a existência de discriminação contra LGBT, apenas 32\% admite ter algum preconceito, o que contrasta com os $4 \%$ obtidos- em pesquisas similares, que enfocavam o preconceito racial ou contra idosos (VENTURI; BOKANY, 2011). O que essa pesquisa parece indicar é que, além da legitimidade social que a violência contra LGBT possui, há a ação importante de convenções sociais acerca do caráter natural da heterossexualidade e que apontam para a homossexualidade como escolha individual - que deve ser mantida no âmbito do privado. A força de tais convenções se expressa na compreensão de que dificuldades decorrentes dessa "escolha" (a violência é encarada nesse sentido) devem ser manejadas pelo próprio sujeito ( $70 \%$ dos entrevistados pela Fundação Perseu Abramo acreditavam que "a discriminação contra homossexuais, bissexuais, travestis e transexuais é uma questão que as pessoas devem resolver entre elas" ao invés de ser objeto de políticas governamentais).

Outra frente de estudos procura explorar a dinâmica da homofobia a partir de entrevistas com potenciais vítimas de discriminação ou agressões. Esse é o caso das pesquisas realizadas pelo Centro Latino Americano em Sexualidade e Direitos Humanos (CLAM/IMS/UERJ), Centro de Estudos de Segurança e Cidadania (CESeC/UCAM) e seus parceiros em diversas capitais brasileiras. Tais pesquisas têm encontrado percentuais bastante consistentes de relatos de discriminação e de agressões entre LGBT participantes das Paradas do Orgulho (CARRARA et al, 2004, 2005, 2006, 2007): entre $61 \%$ e $65 \%$ dos LGBT entrevistados relatam ao menos um episódio de discriminação com base na sexualidade ao longo da vida e entre $56 \%$ e $72 \%$, ao menos um episódio de agressão. Na pesquisa realizada na Parada paulistana de 2005, 40\% dos que disseram ter sofrido ao menos uma agressão motivada pela sexualidade ao longo da vida não relataram aquela que consideraram a agressão mais marcante a ninguém. Entre os que relataram, a maior parte o fez a amigos ou familiares, sendo que menos de $20 \%$ relataram à polícia ou a grupos ativistas.

Assim como a frequência das modalidades de agressão e discriminação investigadas varia de acordo com a articulação entre diversos marcadores sociais de diferença (sexualidade, gênero, classe, raça e geração), o relato da agressão sofrida também varia, de modo que mulheres, em geral, relatam menos que homens; o percentual de relato decresce conforme aumenta o nível de escolaridade; é menor, também, entre brancos e entre os que têm menos de 22 anos ou mais de 40 (FACCHINI et al, 2007). Embora os dados existentes apontem para 
Convenções de gênero, sexualidade e violência: pesquisa com participantes de eventos do Orgulho LGBT de São Paulo - 2009.

algumas zonas de vulnerabilidade produzidas na intersecção de marcadores sociais de diferença, é preciso avançar ainda no sentido de qualificar melhor os resultados obtidos, de maneira a fornecer subsídios para pesquisadores e para a atuação de ativistas e gestores no que concerne à construção de políticas de enfrentamento da homofobia em diferentes contextos.

Inspirada pelos estudos de vitimização conduzidos em Paradas, a pesquisa cujos dados apresentamos procura se aproximar das situações de violência ou discriminação vividas por pessoas que se encontram situadas no campo do que chamamos hoje de LGBT. Trata-se de esforço no sentido de construir uma abordagem qualitativa que se some aos dados encontrados nas pesquisas quantitativas já realizadas em Paradas pelo CLAM, CeSEC e parceiros. Assim, reproduzimos em menor escala a metodologia já consolidada por essas experiências, estabelecendo um segundo objetivo de entrar em contato com os participantes da primeira etapa da pesquisa, convidando-os a conceder uma entrevista em profundidade ${ }^{2}$.

Na etapa quantitativa, temos um perfil mais geral que indica um conjunto de sujeitos predominantemente jovem (60\% tinha até 29 anos e $80 \%$ até 40 anos), com altos níveis de escolarização (51\% iniciaram ou concluíram um curso de nível superior), no qual $60 \%$ é formado por pessoas assignadas ao nascer como do sexo masculino e $50 \%$ são brancos. No momento da pesquisa $82 \%$ estavam trabalhando; $56 \%$ eram assalariados com carteira assinada e cerca de $15 \%$ eram profissionais liberais ou funcionários públicos. A maioria vivia com familiares (39,7\%), seguidos pelos/as que moram com o/a companheiro/a (25\%), sozinhos/as $(21,9 \%)$ ou com amigos/as (10,9\%), sendo que $48,1 \%$ estavam em um relacionamento estável (namoro ou casamento) e 10,3\% possuem filhos. No que diz respeito à "sexualidade agregada": 73,8\% são homossexuais (sendo, 43,8\% homens e 30\% mulheres); $15 \%$ bissexuais (sendo 5,6\% homens e 9,4\% mulheres); $9,4 \%$ trans (travestis e mulheres transexuais $\underline{3}$ ).

\footnotetext{
2 Esta pesquisa se diferenciou de pesquisas anteriormente realizadas na Parada LGBT de São Paulo pela opção por aplicar os questionários em dois eventos do Mês do Orgulho - a Feira Cultural LGBT e a Parada. Além disso, restringimos os entrevistados a LGBT participantes dos eventos, que fossem maiores de 18 anos e residentes na Grande São Paulo, de modo a viabilizar a realização posterior de entrevistas em profundidade. Obtivemos 320 questionários preenchidos e validados e realizamos, posteriormente, 31 entrevistas em profundidade com LGBT que relataram ter sofrido ao menos uma situação de discriminação ou violência. $\mathrm{O}$ conjunto de entrevistados foi composto de modo a obter a maior diversidade possível em termos de classe, geração, cor/raça e "sexualidade agregada" dos respondentes (as diversas identidades auto-atribuídas pelos sujeitos na entrevista da primeira etapa foram agrupadas em categorias mais amplas - homens e mulheres homo e bissexuais e pessoas trans - para que se pudesse diversificar internamente o conjunto da segunda fase).

${ }^{3}$ No conjunto das entrevistas, não surgiu nenhum entrevistado que tenha se identificado
} 
Regina Facchini

Isadora Lins França

No que diz respeito à análise das entrevistas, entendemos que, nessas ocasiões, os sujeitos reconstituem o vivido atribuindo-lhe sentido e emitem enunciados sobre si mesmas que nos dão pistas de como se constituem como sujeitos em meio a contextos de violência. Tentamos compreender quais as linguagens possíveis para falar da violência, o que é dito e para quem, como são colocadas em perspectiva as situações relatadas a partir da produção da experiência ${ }^{4}$ no momento da entrevista (BRAH, 2006). Por vezes, histórias vividas em segredo eram relatadas à pesquisadora, tendo sido guardadas por longo tempo; por outras vezes, situações que para as pesquisadoras apareciam como claramente violentas eram relatadas a propósito de outros assuntos, deixando de ser mencionadas quando o tema da violência era evocado diretamente (DAS, 1999).

Este artigo tem por objetivo colaborar para aprofundar o conhecimento em torno de como a dinâmica da "homofobia" articula gênero, sexualidade e outros marcadores sociais da diferença. Para tanto, debruça-se especialmente sobre os dados obtidos na etapa qualitativa da pesquisa, articulando-os com os dados do quantitativo quando necessário. $\mathrm{O}$ texto está dividido em duas partes: na primeira delas, exploramos convenções sociais acerca de gênero e sexualidade e processos de mudança social a partir dos relatos dos sujeitos e das categorias de classificação e de acusação mobilizadas nas situações de violência relatada, considerando a convivência entre diferentes modelos de classificação da sexualidade. Na segunda parte, procuramos compreender melhor convenções e dinâmicas relacionadas à violência em razão da sexualidade a partir das falas de pessoas que relataram ter sofrido discriminação ou agressão por conta da sua sexualidade na etapa quantitativa da pesquisa.

\section{Homossexualidade como lugar social: convenções, mudança social e injúrias}

O campo de questões envolvendo gênero e sexualidade tem se

como transexual e que tenha sido assignado como do sexo feminino ao nascer, ou seja, que se aproximasse da categoria de "homem trans", que vem ganhando maior visibilidade e servindo à articulação de um sujeito político há pouco tempo (FACCHINI, 2010). Supomos que algumas das experiências de discriminação e violência sofridas pelos "homens trans" sejam similares às sofridas pelas "mulheres trans", mas não descartamos também uma aproximação dessas experiências daquelas sofridas por pessoas identificadas em determinados contextos sociais como sapatões. De todo modo, seria prematuro o esboço de uma análise a esse respeito neste momento.

4 Tomamos a noção de experiência como um processo contingente de significação, por meio do qual processos simultâneos de "inscrição" e "atribuição", fazem com que "o sujeito adquir[a] significado em relações socioeconômicas e culturais no mesmo momento em que atribui significado dando sentido a essas relações na vida cotidiana" (BRAH, 2006, p. 362, grifos da autora).

Latitude, Vol. 7, no 1, pp. 13-32, 2013. 
Convenções de gênero, sexualidade e violência: pesquisa com participantes de eventos do Orgulho LGBT de São Paulo - 2009.

movimentado de maneira muito dinâmica no país nas últimas décadas. As transformações se dão em diferentes esferas, mobilizando diversos atores sociais e gerando polêmicas de amplitude nacional. A homossexualidade e os "LGBT", de modo geral, têm galvanizado boa parte das atenções nesse terreno, firmando-se como um lugar privilegiado para a análise desse processo de mudança.

No domínio das convenções, é preciso pontuar a convivência entre diferentes sistemas de classificação da homossexualidade referida no clássico trabalho de Peter Fry (1982). Embora, nas últimas décadas, tenha se registrado o espraiamento de um sistema de classificações moderno, o par gay/gay ainda divide espaço com o modelo que se funda no par bicha/bofe. Ao mesmo tempo, as interpenetrações entre os diferentes sistemas denotam um contexto marcado pela circulação de saberes e de convenções.

No campo desta pesquisa, notamos tensões entre perceber a homossexualidade como essência, como um tipo de doença ou desvio do natural ou do correto, como uma tendência que se expressa por meio do jeito dissonante em relação a expectativas sociais de gênero ou, por outro lado, como umas das potencialidades da personalidade dos humanos, como lugar do mais íntimo, que só pode ser compartilhado mediante uma relação estreita de respeito e reciprocidade. Essa distinção remete a diferentes maneiras de conjugar a distinção entre hetero e homossexualidade, bem como esta última como lugar social. Remete ainda a diferentes modos de pensar os sujeitos e suas relações com os outros. Não se trata, no entanto, de lugares mutuamente excludentes na vida dos sujeitos de carne e osso.

No rastro desses processos que distinguem hetero e homossexualidade, também se estabelece uma outra fronteira, ainda quase exclusivamente presente entre os assignados ao nascer como do sexo masculino, que separa travestis e transexuais dos homossexuais (FACCHINI, 2010), marcando uma forte distinção entre o que se tem convencionado chamar de orientação sexual e identidade de gênero.

Falamos aqui de processos de classificação nos quais operam relações sociais de poder atravessadas por marcadores de gênero, sexualidade, mas também de classe e geração. Se o mais óbvio ao pensarmos num processo de mudança social seria buscar tais variações olhando para as diferentes gerações de entrevistados, o que o campo nos indica é que há processos de mudança bastante visíveis, mas eles estão também fortemente perpassados por fatores que remetem a classe social, de modo que temos, entre jovens de estratos médios, uma predominância de convenções marcadas por relações igualitárias e recombinações de gênero e sexualidade que tendem a dissociar estes marcadores na produção da homossexualidade como lugar social e, entre pessoas mais velhas de estratos populares, convenções mais próximas ao que Fry (1982) havia chamado de "modelo tradicional". Desse modo, foi comum encontrar relações intraclasse e intergeracionais marcadas por conflitos entre diferentes convenções. Um exemplo 
Regina Facchini

Isadora Lins França

são jovens de estratos médios que se consideram bissexuais, $80 \%$ gay e $20 \%$ hetero ou garotas que estão homossexuais e que relataram, sem muitos conflitos, aos pais o fato de gostarem de pessoas do mesmo sexo, mas que ou se dizem homossexuais para não confundir a cabeça dos pais ou ouvem coisas como Bissexual não existe. Ou é lésbica ou não é. Tem que escolher!

Categorias correntes no "meio LGBT" paulistano, como bi, gilete, maricona, poc-poc, cafuçu, homossexual, entedido/a, sapatão, barbie, sapinha etc, enunciadas como categorias de autoclassificação ou de acusação, nos remetem, então, à produção da diferença no discurso e à dinâmica pela qual os próprios marcadores se constituem, uns por meio dos outros (BRAH, 2006; MCCLINTOCK, 2010; FACCHINI, 2008; FRANÇA, 2010). Mas podem nos conduzir, ainda, a um outro nível de análise, aquele que atenta para os contextos de enunciação e para as relações de identificação e diferenciação que se produzem, com foco no manejo de convenções e na operação de diferenças sociais por parte dos sujeitos. Nessa direção, tais categorias funcionam como operadores de diferenças (FACCHINI, 2008).

A emergência de situações violentas associadas à atribuição de um lugar de bicha ou de sapatão na infância ou adolescência foi bastante comum nos relatos da pesquisa. No conjunto de 320 entrevistados na ocasião dos eventos do Orgulho LGBT de 2009, 40\% declararam a ocorrência de situações de discriminação na escola ou faculdade ao longo da vida. Pouco mais da metade do conjunto que foi entrevistado em profundidade relatou ter vivido situações em que eles mesmos ou colegas muito próximos foram colocados no lugar de bicha ou de sapatão na infância ou no início da adolescência.

Categorias como bicha ou sapatão - ou qualquer outra acusação/injúria que pretenda falar de efeminados ou masculinizadas - são acionadas por todos aqueles que pretendem se considerar fora do alcance desses termos. Isso implica pensar que há uma convenção bastante difundida, segundo a qual há homens/garotos e mulheres/garotas e há riscos de desvios em relação a esses lugares que podem e devem ser controlados coletivamente. Entre os garotos, esse lugar de desvio em relação a gênero é ocupado por categorias como viadinho, bichinha e correlatas. Já entre as garotas, o lugar de desvio em relação a gênero é dividido entre as categorias galinha e sapatão e suas correlatas.

Entre entrevistados assignados como do sexo masculino ao nascer, categorias como bichinha ou viadinho não dizem respeito direta e exclusivamente à sexualidade. Além dos sentidos associados a gênero nessas acusações, vários entrevistados relataram ter sido assim classificados por serem mais limpinhos ou arrumadinhos que os outros, $C D F$, por não falarem palavrões ou não terem habilidade no desempenho de determinadas práticas esportivas ou em brigas com outros meninos. Ser apontado como namoradinho de outros meninos ou ser considerado disponível para brincadeiras de cunho sexual com outros garotos é 
Convenções de gênero, sexualidade e violência: pesquisa com participantes de eventos do Orgulho LGBT de São Paulo - 2009.

apenas parte do lugar de viadinho ou de bichinha, parte essa que não necessariamente precisa ocorrer para que tal lugar social seja atribuído e mantido em relação a um garoto.

Em campo, ouvimos relatos de homens que referem não terem sentido qualquer atração mais significativa ou realizado qualquer brincadeira de cunho sexual com outros garotos e que, ainda assim, ocuparam tal lugar em determinados ambientes durante boa parte da infância. Ouvimos também relatos de entrevistados para os quais o contato com acusações de viadinho chegou à sua vida antes mesmo de terem qualquer desejo por outros garotos ou saberem o que era isso. Em alguns desses casos trata-se de homens que foram, na infância, amigos próximos de meninos que foram colocados no lugar de viadinho.

A força de que se reveste essa acusação faz com que o agenciamento das convenções que a investem tenha passado, na maior parte das vezes nesta pesquisa, pela afirmação da homo ou bissexualidade, afastando-se, no entanto, de qualquer associação entre tal identidade/conduta e a afeminação. Pesquisas recentes sobre homossexualidade entre pessoas assignadas como do sexo masculino no nascimento (FRANÇA, 2010; BRAZ, 2010) também apontam que distinções entre machos e bichas aparecem recorrentemente como elementos problemáticos do processo de construção subjetiva de muitos entrevistados dessas pesquisas. Camilo Albuquerque de Braz (2010) ressalta a valorização de "masculinos" e uma dissociação entre sexualidade, atributos de gênero e atividade e passividade em clubes voltados para a prática de sexo em São Paulo: todos são homossexuais ou gays e devem ser machos, independente de se engajarem como ativos ou passivos nas práticas eróticas. Em sua pesquisa, em três diferentes lugares de sociabilidade e lazer para homossexuais, Isadora Lins França (2010) também indica mudanças nas convenções acerca da "homossexualidade masculina", que dissociam gênero e sexualidade, desvalorizando afeminados ou bichas e empurrando-os para lugares de sociabilidade classificados como hetero.

É preciso ressaltar que as diferentes trajetórias também são moduladas por contextos e habilidades pessoais - França (2010) relata a história de uma bicha que constrói, em sua trajetória, essa posição como vantajosa. No entanto, a maior parte das histórias remetem a um contexto em que convenções que justapõem gênero e sexualidade perdem espaço no campo da homossexualidade masculina, reservando o campo da identidade de gênero como espaço legítimo para aqueles assignados ao nascer como do sexo masculino que são marcados pelo "feminino".

Ao olharmos para as entrevistas com pessoas assignadas ao nascer como do sexo feminino - mulheres bi e homossexuais - salta aos olhos o fato de que haja uma dispersão de categorias usadas para acusações no que diz respeito a gênero e sexualidade em comparação aos assignados como do sexo masculino. Nos relatos de mulheres bi e homossexuais emergiram duas variantes de acusação - puta e sapatão. Essas duas variantes podem estar presentes na entrevista de uma mesma 
Regina Facchini

Isadora Lins França

pessoa e, num mesmo caso relatado pode haver flutuações entre uma ou outra categoria acusatória.

Entre as mulheres entrevistadas, a acusação de sapatão na infância ou adolescência por qualquer diferença de aparência ou conduta pareceu ser menos difundida do que entre os garotos. Ela aparece, nos relatos das entrevistadas desta pesquisa, depois que a garota conta a alguém que tem qualquer interesse diferente por uma outra garota, quando há desconfiança de que ela goste de garotas de um modo que se esperaria que ela gostasse de garotos ou quando seu jeito é tido como masculinizado. Além disso, situações relacionadas a diferenças culturais, étnicas, de classe ou o fato de as crianças e adolescentes serem considerados $C D F$ ou serem muito tímidos, foram tidas como motivações que podem ter levado à atribuição da acusação de viadinhos entre os garotos. Tais diferenças foram lembradas como motivos para a atribuição de acusações não diretamente relacionadas a gênero ou sexualidade, mas a diferenças de outra ordem que encontravam expressões de acusação numa linguagem referente a gênero e sexualidade. Ou seja, gênero e sexualidade funcionavam, aqui, como repertório capaz de traduzir outras diferenças sociais na dinâmica acusatória.

No caso das mulheres, apenas uma mulher de 32 anos cuja performance de gênero era tida como masculina recebeu e continua recebendo a acusação de ser sapatão como xingamento de modo sistemático mesmo quando não está acompanhada por outra mulher. Quando olhamos para as entrevistadas cujas performances de gênero são tidas como femininas, a dinâmica da violência aparece mediada pela ideia de discrição. Num contexto de homossexualidade discreta, os conflitos familiares envolvem a identificaçao da homossexualidade por meio da vigilância do bom comportamento das filhas ou pelo próprio relato das mesmas em busca de apoio. Chantagens afetivas por parte dos pais, agressões verbais ou físicas, isolamento de más influências, trocas de escola e encaminhamento a psicólogos foram comuns nesses casos. Agressões ou isolamento na escola foram registrados, no conjunto de entrevistadas em profundidade, em dois casos. O reequilíbrio das relações com familiares e/ou pessoas da escola foi geralmente obtido pela adoção de uma postura discreta quanto a si e suas relações com mulheres. Outra forma de manejar conflitos familiares e de aplacar o receio de um "caos sexual ou moral" causado pela ideia da filha ter sexo com mulheres passa por ter um relacionamento estável com uma pessoa que obtenha aprovação dos pais e adoção de outros elementos, como ter uma vida profissional bem estabelecida e/ou participar de alguma religião. Essa ideia de "caos sexual e moral" se aplica a vários casos de homens e de mulheres na pesquisa, como o de uma entrevistada bissexual que, aos 21 anos, passou a ter sua bolsa revistada pelos pais em busca de drogas depois que descobriram que ela estava se relacionando com uma mulher.

A questão da discrição, como indicado em Facchini (2008) e em boa parte da literatura sobre o tema, é uma das características mais importantes quando se 
Convenções de gênero, sexualidade e violência: pesquisa com participantes de eventos do Orgulho LGBT de São Paulo - 2009.

pensa o manejo de convenções sociais entre mulheres homossexuais, sejam elas as de estratos médios com mais de 35 anos, as de estratos médios baixos de qualquer idade e, entre as populares, as mais jovens ou as que não se identificam ou são identificadas como extremamente masculinizadas.

Além da discrição, a complexidade classificatória de que se revestem as acusações direcionadas a mulheres aparece associada com a entrada em cena de um outro conjunto de categorias, aquelas relacionadas a ideia de puta, galinha ou qualquer outra que vise a indicar uma mulher de mau comportamento sexual. Predominantemente relacionado ao contexto da heterossexualidade, esse conjunto de acusações emergiu, na maior parte das vezes e com mais intensidade, embora não exclusivamente nessas, nas entrevistas de mulheres auto-classificadas como bissexuais.

As mulheres que se classificaram como bissexuais, assim como os homens que se classificaram desse modo, além de um perfil de classe e escolaridade semelhantes (estratos médios e altos níveis de escolarização), também compartilham uma outra característica: em seus relatos, a identificação do desejo mais intenso envolvendo pessoas do mesmo sexo e/ou a oportunidade de transformá-lo em conduta sexual aparecem apenas depois da adolescência e após terem tido experiências erótico-afetivas que consideraram significativas com o outro sexo. Nos relatos acerca de violência, mulheres bissexuais tenderam a agregar como violência relacionada à sexualidade ocorrências geralmente abordadas na literatura dedicada à "violência de gênero": as diferenças no que diz respeito ao acesso à informação ou possibilidade de fruição da sexualidade quando comparadas a seus irmãos e colegas do sexo masculino; os vários tipos de controle e vigilância, mais ou menos severos e mesmo violentos, de seus comportamentos e aparências com os quais tiveram de lidar em relação a familiares; o fato de serem, mais ou menos eventualmente, acusadas de serem putas ou galinhas; as encoxadas que recebiam em transportes coletivos; parentes mais velhos que eventualmente tocaram seus corpos de modo que lhes diziam que outros homens não poderiam fazer; rapazes, em parte mais velhos, com quem viveram situações ambíguas quanto ao consentimento para sexo no início da vida afetivo-sexual e mesmo uma situação de gravidez e maternidade decorrentes de sexo não consentido na adolescência.

A inserção desse conteúdo nos relatos dessas mulheres nos convida a refletir sobre as relações entre gênero, sexualidade e violência e sobre a "homofobia" a partir de uma outra perspectiva. Os relatos dessas mulheres sinalizam a necessidade de pensar que a homofobia, entendida como relativa a modalidades de violência marcadas pelo fato da vítima ser identificada como homo ou bissexual, ou como travesti ou transexual, apesar de ser uma das formas de violência relacionadas à sexualidade mais visíveis no debate público atual, não é a única modalidade de violência relacionada à sexualidade que pode estar 
Regina Facchini

Isadora Lins França

presente na vida dessas pessoas. Chama também atenção para a necessidade de levar em conta os elementos relacionados à sexualidade, assim como se tem feito com outros marcadores sociais de diferença, ao abordar a "violência de gênero".

Ainda sobre o lugar de mulher e sobre a acusação de ser puta atribuída às mulheres, gostaríamos de finalizar este item pontuando brevemente o fato de que quando sujeitos assignados ao nascer como do sexo masculino são simbolicamente marcados num lugar de mulher, a convenção que separa o universo formado pelos sujeitos classificados como femininos entre mulheres honestas e putas parece atuar. Etnografias recentes envolvendo travestis e transexuais, mais ou menos próximas ao ativismo, chamam atenção para os lugares de putas ou de loucas com os quais são simbolicamente marcadas, seja por operadores dos saberes científicos ou em situações de trocas de acusações mútuas que têm lugar nas guerras classificatórias envolvendo as categorias travesti e transexual no ativismo LGBT (BARBOSA, 2010; CARVALHO, 2011).

Entre entrevistadas que se classificaram como travestis, transexuais ou trangêneros, o relato de situações envolvendo a atribuição do lugar de viadinho na infância ou adolescência esteve presente em todos os casos. A referência à prostituição também esteve presente em todas as entrevistas dessas pessoas na etapa qualitativa desta pesquisa, seja para se distanciar desse lugar ou para se referir a passagens mais ou menos duradouras pelo trabalho no mercado do sexo. Essa recorrência sugere avaliar a hipótese de que os sujeitos assignados como do sexo masculino ao nascer, ao serem identificados com o lugar do feminino, sejam colados à acusação de puta, ou seja, uma mulher de mau comportamento sexual, o que justificaria toda a sorte de violência a que são submetidos/as.

\section{Evento e contexto: preconceito, discriminação e violência}

Os dados produzidos a partir dos eventos do Orgulho LGBT de São Paulo em 2009 indicam altos percentuais de agressão e discriminação motivados pela sexualidade ${ }^{5}$ : $80,6 \%$ dos entrevistados relataram ao menos uma situação de discriminação na vida e $74,7 \%$ relataram ter passado por alguma modalidade de agressão.

No que diz respeito a situações de discriminação, temos os seguintes percentuais: por motivos religiosos - religião da outra pessoa (49,6\%); por grupo de amigos ou vizinhos (48,8\%); em ambiente religioso $(42,2 \%)$; em ambiente familiar

\footnotetext{
${ }^{5}$ Trata-se de mais uma incorporação de estratégia adotada nas pesquisas do CLAM, CESeC e parceiros: dizer que o evento é motivado pela sexualidade é um modo de procurar se fazer entender por entrevistados que não necessariamente manejam classificações como a distinção entre orientação sexual ou identidade de gênero.
} 
Convenções de gênero, sexualidade e violência: pesquisa com participantes de eventos do Orgulho LGBT de São Paulo - 2009.

$(42,2 \%)$; por professores/as ou colegas de escola/faculdade $(39,9 \%)$; em comércio/locais de lazer (33,7\%); por policiais ou em delegacias $(26 \%)$; por profissionais ou serviços de saúde (21,7\%); impedimento de doar sangue $(19 \%)$; emprego e trabalho (19\%); e, em serviços públicos como albergues, subprefeituras, transportes ou banheiros públicos $(17,1 \%)$. No que diz respeito a agressões: verbais (92,5\%); ameaça de agressão (50,2\%); constrangimento no trabalho (36\%); agressão física $(28,9 \%)$; chantagem ou extorsão $(18,4 \%)$; violência sexual $(11,7 \%)$; e boa noite cinderela (5,9\%).

Como indica a literatura (CARRARA ET AL. 2006; FACCHINI, 2007), apesar do alto percentual de eventos de discriminação e/ou de agressões, o percentual de relatos é bastante baixo. Entre aquelas agressões que foram consideradas as mais marcantes, 58,3\% foram relatadas a alguém ou algum orgão, sendo que, destas, $44,5 \%$ foram relatadas a amigos e apenas $16,4 \%$ a policiais. As modalidades de agressão mais relatadas são agressão verbal e agressão física. A agressão física é a modalidade de agressão mais relatada a policiais. Ainda assim, entre os que relataram ter sofrido agressão física $(26 \%)$, pouco menos da metade $(45 \%)$ relataram o fato à polícia.

A análise de dados indica baixo conhecimento de leis ou recursos de apoio a LGBT:

Apesar 51,3\% dos entrevistados afirmarem que conhecem alguma lei ou projeto que beneficie LGBT, apenas $15,7 \%$ do total citou espontaneamente a Lei Estadual 10.948/2001, que pune a discriminação contra LGBT. Enquanto 45,6\% dos entrevistados disseram conhecer órgãos, serviços ou instituições que apoiam LGBT, apenas 6,8\% citaram a Coordenadoria da Diversidade ou um dos dois centros de referência voltados a essa população no município, 3,6\% citaram alguma ONG LGBT (FALCÃO, 2011).

Porém, para além do baixo (re)conhecimento de leis e recursos, há outros fatores que devem ser levados em consideração quando pensamos no silenciamento de situações que podem ser consideradas discriminatórias ou violentas pelos sujeitos e que são motivadas pela sexualidade. A seguir, procuramos compreender como os sujeitos significam tais eventos por meio da análise de como os entrevistados erguem fronteiras entre o que consideram preconceituoso, discriminatório ou violento, assim como pelo que consideram ou não digno de relato. Para tanto, passamos a abordar os resultados obtidos na etapa qualitativa.

Espantou-nos, no que concerne à classificação dos eventos vividos, a precária identificação das situações ocorridas no âmbito familiar como situações de violência. As narrativas sobre conflitos familiares que incluíam situações que poderiam ser classificadas como violentas, no geral, oscilavam entre um tom doloroso e um tom que logo relegava as experiências ao passado e à superação, 
Regina Facchini

Isadora Lins França

diminuindo a importância das mesmas. Não foram raras as situações em que, após a narrração de histórias de exclusão, discriminação e violência, os entrevistados encerravam o assunto como se colocassem uma pedra em cima de tudo: mas agora está tudo bem.

Uma possibilidade interpretativa dessas situações talvez seja considerar o "trabalho do tempo" e as situações de violência e exclusão familiar também como possíveis de serem agenciadas pelos sujeitos, seguindo Veena Das (1999). Tratamos de relações cotidianas e de laços perenes, que abrem espaço para agenciamento e reestruturações. Os modos de agenciamento de um lugar familiar perpassado pela violência são variados: incorporam o diálogo e o arrependimento dos pais, mas também a reescrita desse lugar por meio de um esforço dos filhos por se mostrarem responsáveis e ascenderem socialmente.

Em parte das situações em que a violência familiar é referida como violência de fato e elencada entre os acontecimentos marcantes na vida, é muito comum que tenha havido episódios de agressão física e que as relações familiares não tenham se apaziguado ou restaurado desde então, estabelecendo um distanciamento que parece pouco remediável.

Entre os entrevistados que mencionaram situações de violência física em âmbito familiar há uma diferença quando tratamos de homens homossexuais e travestis e transexuais e quando tratamos de mulheres: se para os primeiros a violência física parece se concentrar no período da infância, entre as mulheres a violência física inicia na infância e adentra a adolescência ou aparece apenas na adolescência ou idade adulta. Se para os primeiros, a agressão física se baseia num comportamento que é visto como inadequado em termos de gênero, para as segundas, há a violência quando revelam ou os pais percebem que têm um relacionamento com uma garota ou que gostam de mulheres ou quando, para o pai, transgridem fronteiras entre a mulher honesta e a puta.

Entre as situações que são imediatamente e inequivocamente referidas como discriminação ou violência, a agressão física é uma das situações mais reconhecidas como tal, especialmente quando acontece por desconhecidos e na adolescência ou idade adulta. Tais situações pontuais, incrustadas no tempo, não se prestam a grandes remanejamentos.

Os casos de agressão em espaço público, tais como relatados, foram motivados pelo reconhecimento da sexualidade da vítima como "nãoheterossexual", como já sinalizado na literatura (CARRARA; VIANNA, 2006). Os casos relatados de agressão física em espaço público - o que vale também para agressões verbais e ameaça de agressão física - concentram-se -em entrevistados que 1) são reconhecidos como bichas ou sapatões, no bairro ou espaços públicos quaisquer; 2) não são reconhecidos a partir de sua expressão de gênero, mas pela exposição de afeto em público, principalmente por estarem de mãos dadas com alguém do mesmo sexo; 3) são reconhecidos como travestis ou transexuais.

Latitude, Vol. 7, no 1, pp. 13-32, 2013. 
Convenções de gênero, sexualidade e violência: pesquisa com participantes de eventos do Orgulho LGBT de São Paulo - 2009.

Encontramos relatos de agressão física em espaços públicos em todos os estratos sociais e cor/raça. Também não há uma divisão sensível por idade ou sexualidade, já que temos relatos de agressão física desse tipo em todas as identidades (exceto entre as mulheres bissexuais) e em todas as faixas de idade. Talvez a única posição que acarreta uma menor exposição à violência desse tipo seja a que conjuga mulheres a uma expressão de gênero feminina. Contudo, foram frequentes os relatos de ameaça de agressão e de agressão verbal contra mulheres.

Apesar de as situações de agressão física em espaços públicos estarem distribuídas de modo mais ou menos constante no conjunto de entrevistados, cabe enfatizar que, como já demonstraram outras pesquisas, as travestis e transexuais relatam eventos desse tipo em muito maior número que os outros perfis entrevistados. Nesse contexto, como demonstra a literatura, a violência policial também se apresenta de forma muito intensa, por meio de constantes achaques, ameaças, espancamentos e prisões.

Mulheres e travestis e transexuais relatam também a discriminação em serviços de saúde com mais frequência, diferente dos homens em geral. Tais depoimentos sinalizam como o preconceito e a discriminação associados a gênero e sexualidade estão relacionados a julgamentos morais que influenciam o exercício dos saberes médicos e o acesso à saúde.

Situações de preconceito e discriminação que também foram relatadas de modo bastante claro se dão no contexto do trabalho. Há, neste aspecto, situações evidentes de demissão, constrangimento ou assédio moral, que se distribuem de forma bastante dispersa entre os perfis. Há, ainda, uma exclusão mais sutil, que se revela na dificuldade ou mesmo interrupção da vida profissional com a transição em direção a uma apresentação pessoal relacionada ao sexo oposto, que ocorre no caso de travestis e transexuais; o medo constante e a situação constrangedora de ter de ouvir comentários negativos sobre a homossexualidade em empregos em que as pessoas não se sentem à vontade para revelar sua identidade sexual; a sensação de não ter oportunidades de galgar promoções no trabalho a partir da revelação da identidade sexual; a exclusão do mercado de trabalho ou a restrição a determinadas profissões.

Em relação àquelas experiências em que as pessoas têm sentimentos conflitantes a respeito da violência sofrida ou esta é difícil de delimitar como tal, estão as experiências relacionadas à violência de cunho institucional, à violência sexual, ao silenciamento e as que se imiscuem ao cotidiano. São situações em que o repertório e vocabulário dos entrevistados encontram limites para expressar: aquilo poderia mesmo ser denominado de violência? Como traduzir uma sensação permanente de opressão e silenciamento como violência? Tratamos de algo "denunciável"? Se sim, para quem denunciar? Quem reconhecerá aquela experiência como violência?

Um número considerável de entrevistados faz referência a uma violência 
Regina Facchini

Isadora Lins França

que perpassa sua trajetória de vida e seu dia a dia, sinalizando um contexto que percebem como violento e não um evento com início, meio e fim delimitados claramente no espaço-tempo. É quase como uma sensação que pouco se presta à descrição verbal, contrastando com os casos de agressão física, não raro contados em detalhe.

Um caso especial no que diz respeito à ideia de invisibilidade e silenciamento de suas identidades é o relatado pelos entrevistados que se classificaram como bissexuais. Quase todos enfatizaram, de diferentes formas, a estranha sensação de "não-lugar". Uma experiência marcante, nesse sentido, é o não-reconhecimento de suas relações afetivas com pessoas do mesmo ou de outro sexo, com base na crença de que o desejo deve se orientar apenas em direção a um dos sexos, apresentando-se de forma constante e linear.

No que concerne à violência institucional, há uma dificuldade em lidar com a violência sofrida quando não se tem apoio ou quando essa violência está justificada na ordem do Estado ou em saberes socialmente legitimados. Uma das dificuldades nesse sentido é, mais do que encontrar uma instância de denúncia, a necessidade de encontrar em quaisquer interlocutores a possibilidade de compartilhamento do vivido e do reconhecimento daquela experiência como violência. Um dos relatos, de uma travesti que foi internada compulsoriamente em um serviço de saúde mental, expõe a complexa busca de interlocutores que reconhecessem o que havia vivido como violência, em contraposição ao que profissionais de saúde denominavam como "cuidado". Nesse caso, o movimento social forneceu um ambiente a partir do qual aquela experiência foi elaborada e onde encontrou uma possibilidade de narrativa.

Por último, uma modalidade de violência que foi absolutamente omitida nas entrevistas em profundidade foi o golpe "Boa Noite Cinderela", relatado por dois entrevistados homossexuais no momento da aplicação do questionário quantitativo, mas não mencionada novamente nas entrevistas em profundidade que realizamos com esses mesmos participantes. Se, para as outras experiências aqui citadas, os entrevistados encontravam dificuldades para decodificar e narrar as situações vividas a partir de seu repertório, no caso das vítimas do golpe, embora seja mencionado vagamente o receio de ser vítima ou experiências ocorridas com amigos, não há menção à situação de violência sofrida pelo próprio entrevistado. Eventualmente pode haver, aqui, um sentimento de ter se exposto a uma situação de risco a partir da interação com parceiros desconhecidos. Ao mesmo tempo, como o golpe pressupõe situação de interação sexual - e mesmo como é comum a situações de violência sexual - o sentimento de vergonha pode operar nesse silenciamento a respeito da própria experiência quando relatadas situações de violência vividas. Segundo um dos entrevistados, por exemplo, que narra já ter socorrido três amigos vítimas do golpe, a denúncia do caso não era uma possibilidade avistada pelas vítimas, tomadas por um sentimento de vergonha e 
Convenções de gênero, sexualidade e violência: pesquisa com participantes de eventos do Orgulho LGBT de São Paulo - 2009.

humilhação, bem como de impotência diante da falta de provas ou desconhecimento do paradeiro do agressor.

Acreditamos que a baixa presença da formalização de denúncias esteja associada às dificuldades relacionadas às fronteiras tênues entre o que se reconhece ou não como violência, como em boa parte dos casos mencionados acima. Entretanto, não poderíamos afirmar que apenas isso possa explicar a ausência de denúncia, que parece se tratar de algo que ultrapassa a esfera da decodificação da experiência vivida como violência. Mesmo nos casos em que os eventos narrados são inequivocamente afirmados como violência em razão da sexualidade, o índice de denúncia é bastante baixo: no conjunto geral de entrevistas realizadas, dos 12 entrevistados que afirmaram ter alguma vez na vida sofrido agressão física em idade adulta em razão da sua sexualidade, apenas dois formalizaram denúncia a instituições de segurança pública.

Há ainda as situações que as pessoas consideram difícil de comprovar, notadamente envolvendo violência sexual ou assédio moral no ambiente profissional. O sentimento de desproteção frente a uma denúncia, ou seja, a sensação de que denunciar é evidenciar um conflito e ter de lidar com ele sozinho até que haja algum desenrolar mais significativo por parte de um sistema judiciário moroso e ineficiente desestimula parte dos entrevistados a denunciar nos contextos em que agressores são conhecidos ou que a agressão não é muito grave, ou seja, em que uma denúncia pode transformar um episódio suportável numa ameaça à integridade física.

Entre as justificativas mais citadas nas entrevistas para a ausência de denúncia estão o medo de se expor, ou seja, de ter sua identidade sexual revelada de alguma maneira e registrada em livros públicos; a sensação geral de que não vai dar em nada, reveladora de uma descrença geral no aparato judiciário; e o medo de sofrer novo preconceito nas delegacias ou pelos policiais, que não estariam preparados para lidar com questões desse tipo.

As possibilidades de denúncia parecem ainda mais difíceis quando o autor da agressão é policial. Trata-se de situação relatada como cotidiana por travestis que fazem programa e como esporádicas por outros entrevistados (notadamente os que são identificados como bicha ou sapatão), mas cuja possibilidade de denúncia é tida como remota na maioria dos casos.

Um último contexto de difícil denúncia foi apontado por dois entrevistados moradores de conjunto habitacional e comunidade, ambos na extrema zona leste da cidade. Ambos criticaram a insistência geral na ideia de que é importante denunciar casos de violência, preconceito e discriminação, lembrando que, onde moram, a violência raramente é arbitrada pela polícia. Recorrer à polícia, nesses lugares, por conta de preconceito, discriminação ou violência, significa colocar em risco as atividades ilícitas de pessoas respeitadas no local, o que é muito mal visto. Ao mesmo tempo, uma visita da polícia ao agressor pode fazer com que a 
Regina Facchini

Isadora Lins França

retaliação à vítima ou à sua família apareça de modo muito intenso. As estratégias para se lidar com a violência nesses lugares são duas: recorrer a alguém respeitado na área para repreender o agressor ou revidar a agressão sofrida. As duas estratégias, porém, são arriscadas se a vítima não é pessoa de respeito na área, ou seja, é preciso ter uma boa reputação, conquistada a partir de uma postura de relativo distanciamento de outros moradores, que impeça que qualquer atitude seja tomada como insinuação sexual ou que ofenda determinados valores morais.

Histórias parecidas foram relatadas por outros entrevistados, acontecendo a partir do vácuo institucional que impossibilita a denúncia ou que se recorra a alguma outra instância que não o enfrentamento - como no caso relatado - ou mesmo de outras situações. Fazem parte das estratégias individuais de manejo, contorno ou enfrentamento da violência que, escapando ao escopo do que nos propusemos a analisar com mais profundidade neste trabalho, devem ser consideradas com cuidado em outro momento.

Neste artigo, procuramos articular diferentes possibilidades de análise de resultados referentes a preconceito, discriminação e violência relacionados às pessoas convencionalmente situadas sob a categoria de LGBT. Como vimos, tratamos de fenômenos multifacetados e plurais, cuja definição é sempre contextual. Dessa maneira, optamos por trabalhar os dados considerando as diversas posições subjetivas e a articulação de marcadores de diferença social em interação com sexualidade, atentas a como diferentes lugares que os sujeitos podem habitar em relação a gênero e sexualidade se relacionam com dinâmicas de violência.

A preocupação em dar conta de contextos tão diversos trazidos pelas 31 entrevistas qualitativas está relacionada à análise presente na primeira parte deste artigo, em que procuramos contribuir para a compreensão de como a violência encontra-se articulada a diferentes convenções acerca de gênero e sexualidade e aos lugares de acusação que daí decorrem. As categorias de acusação e os processos de exclusão, estigmatização e violência com base na atribuição de um lugar de viadinho, puta e sapatão dos entrevistados na infância e adolescência foram analisados a partir do modo como os entrevistados dão sentido a sua experiência no momento das entrevistas, possibilitando entender como os sujeitos são interpelados por esses lugares e quais as possibilidades de agência e as limitações que daí decorrem.

Por outro lado, embora reconheçamos que este estudo está situado no campo dos trabalhos que se têm dedicado à compreensão das dinâmicas da "homofobia", cabe sinalizar que esta categoria, tal como entendemos, deve ser tomada sob-rasura? Dada sua capacidade de comunicação e articulação política, a

Latitude, Vol. 7, nํ 1, pp. 13-32, 2013. 
Convenções de gênero, sexualidade e violência: pesquisa com participantes de eventos do Orgulho LGBT de São Paulo - 2009.

categoria "homofobia" segue mostrando-se útil para referir o conjunto de eventos e experiências aqui mobilizados, mas é de pouca utilidade para a sua compreensão se não for empregada de maneira a considerar a articulação de diferentes marcadores sociais de diferença na produção do que se refere genericamente como "homofobia" - ressaltando-se, ainda, que cada um desses marcadores se constitui por meio dos outros. A segunda parte deste trabalho, debruçou-se sobre essa complexa interação a partir dos relatos de preconceito, discriminação e violência obtidos nas entrevistas, levando em conta ainda os processos pelos quais a violência encontra expressão e reconhecimento nas narrativas e resolução - ou não - nos instrumentos formais dos quais se dispõe atualmente para o enfrentamento da violência contra LGBT. Consideramos que quaisquer políticas públicas destinadas ao combate da violência nesse terreno terá forçosamente de encontrar caminhos para lidar com o quadro complexo aqui sinalizado, num esforço de equacionar as diferentes maneiras pelas quais a violência atinge e é percebida como tal por essa população.

\section{Referências}

BARBOSA, B. C. Nomes e diferenças: uma etnografia dos usos das categorias travesti e transexual. 2010. Disssertação (Mestrado em Antropologia Social) - Faculdade de Filosofia, Letras e Ciências Humanas, Universidade de São Paulo, São Paulo.

BRAH, A. Diferença, diversidade, diferenciação. Cadernos Pagu, Campinas, n. 26, pp. 329-376, 2006.

BRAZ, C. A. À Meia-Luz - uma etnografia imprópria em clubes de sexo masculinos. 2010. Tese (Doutorado em Ciências Sociais) Instituto de Filosofia e Ciências Humanas, Universidade Estadual de Campinas, Campinas.

CARRARA, S. O Centro Latino-Americano em Sexualidade e Direitos Humanos e o "lugar" da homossexualidade. In GROSSI, M. P. et al. Movimentos sociais, educação e sexualidades. Rio de Janeiro, Garamond, 2005, pp. 17-24.

CARRARA, S.; RAMOS, S.; CAETANO, M. Política, direitos, violência e homossexualidade. Pesquisa 9 ${ }^{\underline{a}}$ Parada do Orgulho GLBT - Rio 2003. Rio de Janeiro: CEPESC, 2004.

CARRARA, S.; RAMOS, S. Política, direitos, violência e homossexualidade. Pesquisa $9^{a}$ Parada do Orgulho GLBT - Rio 2004. Rio de Janeiro: CEPESC, 2005.

CARRARA, S.; RAMOS, S.; SIMÕES, J.; FACCHINI, R. Política, direitos, violência e homossexualidade. Pesquisa 9a Parada do Orgulho GLBT - São Paulo 2005. Rio de 
Regina Facchini

Isadora Lins França

Janeiro: CEPESC, 2006.

CARRARA, S.; RAMOS, S.; LACERDA, P; MEDRADO, B., VIEIRA, N. Política, direitos, violência e homossexualidade. Pesquisa 5 a Parada da Diversidade Pernambuco 2006. Rio de Janeiro: CEPESC, 2007.

CARRARA, S; VIANNA, A. "As vítimas do desejo": os tribunais cariocas e a homossexualidade nos anos 1980. In: PISCITELLI, A.; GREGORI, M. F.; CARRARA, S. (Ed.) Sexualidades e saberes: convenções e fronteiras. Rio de Janeiro: Garamond, 2004.

CARRARA, S.; VIANNA, A. R. B.. "Tá lá o corpo estendido no chão...": a violência letal contra travestis no município do Rio de Janeiro. Physis. Rio de Janeiro, vol.16, n.2, 2006, pp. 233-249.

CARVALHO, M. F. Que mulher é essa? Identidade, política e saúde no movimento de travestis e transexuais. Dissertação (mestrado em Saúde Coletiva). Instituto de Medicina Social, Universidade do Estado do Rio de Janeiro, Rio de Janeiro, 2011.

DAS, Veena. Fronteiras, violência e o trabalho do tempo: alguns temas wittgensteinianos. Revista Brasileira de Ciências Sociais, São Paulo, vol. 14, n. 40, pp. 31-42, 1999

FACCHINI, Regina. Entre umas e outras: mulheres, (homo)sexualidades e diferenças na cidade de São Paulo. Tese (Doutorado em Ciências Sociais) Instituto de Filosofia e Ciências Humanas, Universidade Estadual de Campinas, Campinas, 2008.

- Convenções em movimento: separações e articulações de gênero e sexualidade entre LGBT. In Fazendo Gênero 9: Diásporas, diversidades, deslocamentos. Florianópolis, UFSC, 2010

. Relatório Final do Projeto "Mulheres, sexualidades, diferenças e mudança social na cidade de São Paulo". Campinas, 2011. (mimeo)

FACCHINI, R; FRANÇA, I. L.; VENTURI, G. Sexualidade, cidadania e homofobia: pesquisa 10a․ Parada do Orgulho GLBT de São Paulo - 2006. São Paulo: APOGLBTSP, 2007.

FALCÃO, T. H. O. Homofobia e silêncio: (des)conhecimento de leis, convenções sobre ativismo e denúncia da violência. Trabalho apresentado ao XV Congresso Brasileiro de Sociologia. Curitiba, 2011 [Sociólogos do Futuro].

FRANÇA, I. L.. Na ponta do pé: quando o black, o samba e o GLS se cruzam em São Paulo. In: BENÍTEZ, M. E. D.; FIGARI, C. E. (eds.). Prazeres dissidentes. Rio de Janeiro: Garamond, 2009.

Consumindo lugares, consumindo nos lugares: homossexualidade, consumo e produção de subjetividades na cidade de São Paulo.Tese (Doutorado em Ciências Sociais) Instituto de Filosofia e Ciências Humanas, Universidade Estadual de Campinas, Campinas, 2010.

FRY, P. Da hierarquia à igualdade: a construção histórica da homossexualidade no Brasil. In: . Para Inglês Ver: identidade e política na cultura brasileira. Rio de 
Convenções de gênero, sexualidade e violência: pesquisa com participantes de eventos do Orgulho LGBT de São Paulo - 2009.

Janeiro: Zahar, pp. 87-115, 1982.

McCLINTOCK, A. Couro imperial: raça, gênero e sexualidade no embate colonial. Campinas: Editora da Unicamp, 2010.

MOTT, L. Homofobia: A violação dos direitos humanos dos gays, lésbicas e travestis. Salvador, Grupo Gay da Bahia, 1997.

MOTT, L. Violação dos Direitos Humanos e Assassinato de Homossexuais no Brasil. Salvador, Grupo Gay da Bahia, 2000.

RAMOS, S. Violência e homossexualidade no Brasil: as políticas públicas e o movimento homossexual. In: GROSSI, M. P. et al. Movimentos sociais, educação e sexualidades. Rio de Janeiro: Garamond, 2005.

VENTURI, G.; BOKANY, V. (Ed.). Diversidade sexual e homofobia no Brasil. São Paulo: Editora Fundação Perseu Abramo, 2011. 